University of Louisville

ThinkIR: The University of Louisville's Institutional Repository

Electronic Theses and Dissertations

$5-2006$

\title{
The acute effects of dynamic and ballistic stretching on vertical jump height, force, and power.
}

Jason Reed Jaggers

University of Louisville

Follow this and additional works at: https://ir.library.louisville.edu/etd

\section{Recommended Citation}

Jaggers, Jason Reed, "The acute effects of dynamic and ballistic stretching on vertical jump height, force, and power." (2006). Electronic Theses and Dissertations. Paper 673.

https://doi.org/10.18297/etd/673

This Master's Thesis is brought to you for free and open access by ThinkIR: The University of Louisville's Institutional Repository. It has been accepted for inclusion in Electronic Theses and Dissertations by an authorized administrator of ThinkIR: The University of Louisville's Institutional Repository. This title appears here courtesy of the author, who has retained all other copyrights. For more information, please contact thinkir@louisville.edu. 


\title{
THE ACUTE EFFECTS OF DYNAMIC AND BALLISTIC STRETCHING ON VERTICAL JUMP HEIGHT, FORCE, AND POWER
}

\author{
By \\ Jason Reed Jaggers \\ B.S. University of Louisville, 2004
}

\begin{abstract}
A Thesis
Submitted to the Faculty of the Graduate School of the University of Louisville in Partial Fulfillment of the Requirements for the Degree of
\end{abstract}

Master of Science

Department of Health and Sport Sciences

University of Louisville

Louisville, Kentucky

May 2006 
THE ACUTE EFFECTS OF DYNAMIC AND BALLISTIC STRETCHING ON VERTICAL JUMP HEIGHT, FORCE, AND POWER

$$
\text { By }
$$

Jason Reed Jaggers

B.S., University of Louisville, 2004

A Thesis Approved on

April 6 ${ }^{\text {th }}, 2006$

by the following Thesis Committee:

Thesis Director 


\section{ACKNOWLEDGMENTS}

First and foremost I would like to thank my Thesis Advisor, Dr. Ann Swank, for all of her patience and guidance in helping me through this learning experience. Her comments, critiques, and constant feedback not only enhanced my writing skills, but my research skills as well. She stood behind me and this project every step of the way, and for that I am grateful.

I would also like to thank my fellow graduate students, Robb Beyer and Mark Grabina, for all the help they provided throughout the testing process. And also my thesis committee members, Dr. Kara Gallagher, Dr. Chong Lee, and Dr. Karen Frost, for their time and effort put into this project as well as my writing. 


\begin{abstract}
THE ACUTE EFFECTS OF DYNAMIC AND BALLISTIC STRETCHING ON VERTICAL JUMP HEIGHT, FORCE, AND POWER

Jason R. Jaggers

April $6^{\text {th }}, 2006$
\end{abstract}

The purpose of this study was to compare the differences between 2 sets of ballistic stretching and 2 sets of a dynamic stretching routine on vertical jump performance. The intraclass reliability coefficients for maximum jump height, force, and power were also assessed using the Kistler Quattro Jump® force plate. METHODS: Ten healthy male college students, ages 22 to 34 years, volunteered to participate in this study. All subjects completed three individual testing sessions on three non-consecutive days. On each day the subjects completed one of three treatments (no stretch, ballistic stretch, and dynamic stretch). A paired samples t-test was used to test the effects of ballistic and dynamic stretching, respectively, on jumping height, force, and power performance scores. Hoyt's analysis of variance model, (MSs-MSi)/MSs, was used to estimate the reliability coefficients on jumping performance scores across three different trials. RESULTS: A paired samples t-test documented that there were no statistical differences in jumping height, force, or power between no stretch and ballistic stretch, and between no stretch and dynamic stretch. The intraclass reliability coefficients were $>.99$ for jumping height, $>0.94$ for jumping force, and $>.99$ for jumping power. CONCLUSION: Both ballistic and dynamic stretching showed nonsignificant effects on vertical jumping performance in 
college male students, but the reliability coefficients were very high to measure jumping height, force, and power using the Kistler Quattro Jump ${ }^{\circledR}$ force plate. 


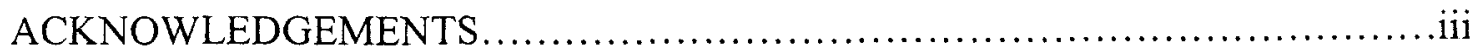

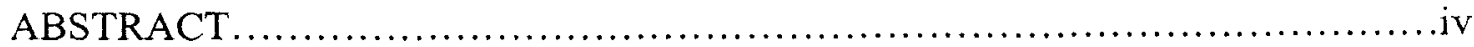

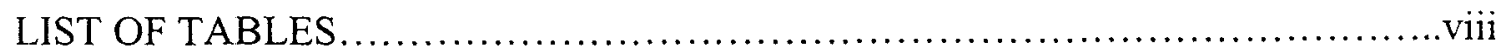

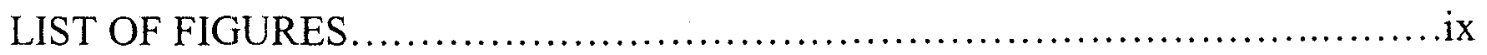

CHAPTER

I. INTRODUCTION ...............................................

II. LITERATURE REVIEW ....................................... 6

Purpose of Stretching............................................. 6

Vertical Jump Testing.........................................6

Types of Stretches.............................................. 8

Stretching and Performance......................................11

Stretch Shortening Cycle.........................................13

III. METHODOLOGY ............................................... 16

Power Analysis................................................. 16

Subjects....................................................... 16

Experimental Design............................................. 16

Stretching Protocol.................................................

Statistical Analysis..............................................23

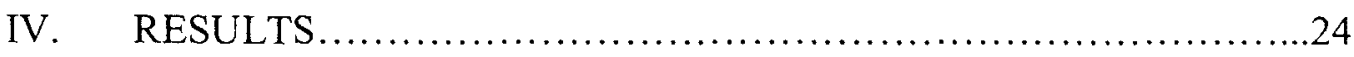

Effects of Ballistic Stretching....................................24 
Effects of Dynamic Stretching...................................28

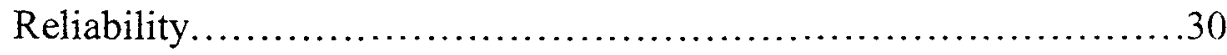

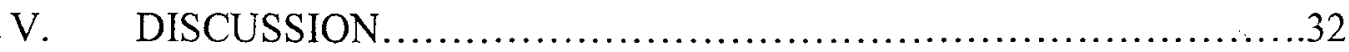

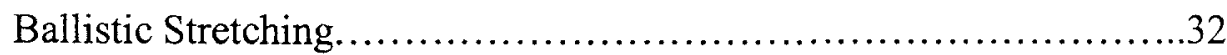

Dynamic Stretching............................................. 34

Reliability.......................................................

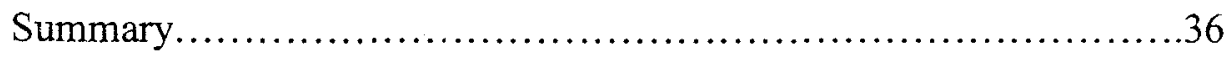

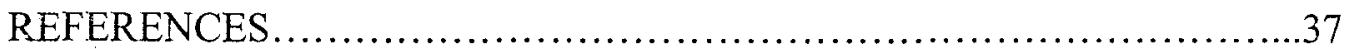

APPENDICES

Informed Consent Form..........................................41

Participant Information.......................................... 45

Medical History Questionnaire ..................................46

Dataset.......................................................... 49

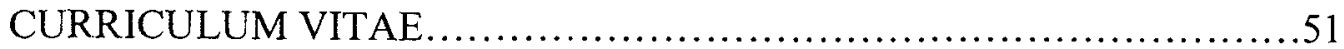




\section{LIST OF TABLES}

TABLE

PAGE

1. Previous Investigations Testing Acute Effects of Stretching. 12

2. Means and Standard Errors for No Stretch, Ballistic Stretch, and Dynamic Stretch. .25

3. Intraclass Reliabilty and Standard Errors of Measurement for the height, force, and power measurement between subjects. 


\section{LIST OF FIGURES}

FIGURE

PAGE

1. Experimental Design.............................................. 18

2. Comparison of jump Height between subjects (No Stretch vs.

Ballistic Stretch).

3. Comparison of jump Power between subjects (No Stretch vs.

Ballistic Stretch).

4. Comparison of jump Force between subjects (No Stretch vs.

Ballistic Stretch).

5. Comparison of jump Height between subjects (No Stretch vs.

Dynamic Stretch). .29

6. Comparison of jump Power between subjects (No Stretch vs.

Dynamic Stretch).

7. Comparison of jump Force between subjects (No Stretch vs.

Dynamic Stretch) 


\section{CHAPTER 1 \\ INTRODUCTION}

Athletes routinely perform static stretching as part of a warm-up prior to exercise and/or competition to reduce the risk of injury and increase performance. The American College of Sports Medicine (ACSM) recommends flexibility training a minimum of 2 to 3 days per week [1]. The four types of stretching techniques are static stretching, ballistic stretching, proprioceptive neuromuscular facilitation (PNF), and dynamic stretching. Past studies have shown that increasing range of motion (ROM) with static stretching increases joint movement leading to an improvement in performance and possibly reducing the risk of injury $[2,3]$. However, the effects of acute stretching on performance or risk of injury has recently been questioned [4-8].

Several investigators have focused on the optimal amount of time to perform a stretch that results in increased ROM [4, 9-12]. Cumulative results indicate that PNF results in larger ROM gains in comparison to static stretching; however the need for a partner limits the use of this technique. Since static stretching can be performed without a partner, it has become the preferred method for increasing ROM. More recent investigations have studied the acute effects that stretching has on performance. Some of these studies have concluded that acute stretching neither helped nor inhibited performance[13-15], whereas other studies have demonstrated negative performance 
effects [7, 16-19]. This negative effect has also been observed in vertical jump performance $[15,18]$.

The vertical jump is widely accepted as a test of maximal leg power and is a common movement executed in many athletic events including basketball, volleyball, and track and field[20]. Knudson et al. studied the effect of static stretching on vertical jump performance. They found that performing 3 sets of static stretches held for 15 seconds each had no significant effect on vertical jump performance[15]. Another study tested the effects of 3 sets of static stretching and found a significant decrease in vertical jump performance when the stretch was held for 30 seconds [14]. Similarly, Behm et al. found a decrease in force and balance after performing 3 sets of static stretching held for 45 seconds each [19]. Even performing one set of static stretches has shown to have a negative effect on leg extension power [21]. Other studies have found decreases in power output and muscle force as a result of acute static stretching and PNF as well [7, 20, 22]. Cumulative results indicate a negative impact of static stretching and PNF on performance; thus, there is a need for evaluating other stretching strategies for effective warm-up.

Only one study examined the effect of ballistic stretching on jumping performance and found no significant difference between static stretching or ballistic stretching on vertical jump performance in trained women [13]. However, Yamaguchi et al. found that dynamic stretching increased leg extension power significantly [21]. Since the vertical jump is used as a test for maximal leg power then performing dynamic stretching as part of a warm-up prior to executing the vertical jump should lead to similar improvements as found by Yamaguchi et al. 
Vertical jump can be measured through a variety of different methods. One method is a simple wall and chalk technique in which the testee places chalk on their fingertips and then jumps against a wall marking the highest point reached with their fingers. Other methods include Just Jump or Run ${ }^{\circledR}$, Long Jump Test ${ }^{\circledR}$, Jump Rack ${ }^{\circledR}$, or the more commonly used Vertec $囚$. More sophisticated methods that measure more than just maximum jump height involve the use of force plates.

One such force plate is the Kistler Quattro Jump ${ }^{\circledR}$ (Amherst, NY 14228). Along with maximum jump height, it also measures the force, power, and endurance of the leg muscles. The only research involving the reliability of using a force plate to measure jump height is that of Isaacs et al[23]. They compared the Just Jump System ${ }^{\circledR}$ (Hunstville, AL 35802) with the Vertec ${ }^{\circledR}$ (Hilliard, OH 43026) to measure maximum jump height. Their findings concluded that there was a significant difference between the two tests [23]. Compared to the Vertec $®$, the Just Jump System ${ }^{\circledR}$ measured the vertical jump .93 inches higher. The Just Jump System ${ }^{\circledR}$ is similar to a force plate such as the Kistler Quattro Jump ${ }^{\circledR}$ where jump height is calculated by flight time. Since the reliability of the Kistler Quattro Jump® has never been tested, the data obtained in this investigation will be used to test the intraclass reliability for measuring jump height, force, and power by using the Kistler Quattro Jump ${ }^{\circledR}$.

Jumping is a movement that is executed via the stretch-shortening cycle. The stretch-shortening cycle is a process of increasing force development enhanced by elastic muscle energy. It is believed that static stretching inhibits the stretch shortening cycle and suppresses the central nervous system resulting in a negative performance effect [24]. Sudden movements, such as jumping or throwing, cause elastic structures to be stretched. 
Immediately after the muscle is stretched, it actively contracts, with the recoil of the elastic elements assisting in force development [25]. Similar sudden movements associated with the stretch shortening cycle are found in dynamic stretches which is why dynamic stretching may be a more effective stretch than ballistic, static, or PNF prior to competition.

Dynamic stretching raises core body and deep muscle temperatures, stimulates the nervous system, decreases the inhibition of antagonist muscles, increases postactivation potentiation and possibly reduces the risk of injury $[21,24]$. As a result of these effects, dynamic stretching may enhance force development and vertical jump performance similar to the enhancements achieved by dynamic stretching on leg extension power observed by Yamaguchi et al[21]. However, further research is needed to draw any conclusions of the effects of acute dynamic stretching on performance.

To our knowledge, only one study has examined the effects of ballistic stretching on performance, thus future research on acute ballistic stretching is warranted. It is unclear whether ballistic stretching has a positive effect on performance in male subjects. Due to the lack of research, this investigation will include a ballistic stretching routine as part of its methods to determine if ballistic stretching has any effect of vertical jump height, force, and/or power.

\section{$\underline{\text { Purpose }}$}

The purpose of this study is to compare two sets of ballistic stretching and two sets of a dynamic stretching routine on vertical jump performance. The data obtained from this investigation will also be used to investigate the intraclass reliability for 
measuring maximum jump height, force, and power using the Kistler Quattro Jump® force plate.

\section{Hypothesis}

The primary research hypotheses are:

(1) Performing two sets of dynamic stretches as part of a warm-up prior to a vertical jump test will increase overall performance of the vertical jump.

(2) Performing two sets of ballistic stretches will not have a significant effect on vertical jump performance

(3) There will be a high intraclass reliability for measuring maximum jump height, force, and power. 


\section{CHAPTER II}

\section{LITERATURE REVIEW}

This literature review discusses the findings from past research on the purpose of stretching, the different types of stretching and their benefits/detriments, the lasting effects of stretch, stretching and performance, as well as vertical jump testing techniques.

\section{Purpose of Stretching}

The term "stretching" can apply to two different types of activities: stretching as part of a warm-up and stretching to increase flexibility/ROM. The literature reviewed showed very little support for static and PNF stretching as a warm-up, leading to the conclusion that stretching prior to physical activity results in performance decrements[ $[14$, $18,19,26-28]$. However, there are countless benefits that can be obtained when one stretches to increase flexibility[4, 29-31]. This increase in ROM is accomplished primarily through a series of static stretches held for 30-45 seconds or longer. PNF stretching has also been shown to have a positive effect on increasing flexibility, however PNF requires a partner for effective use [12, 32].

\section{Vertical Jump Testing}

Measuring an athlete's level of fitness is imperative to determine a training program's effectiveness. Coaches and athletic trainers will often assess an athlete's 
performance skills throughout the season to measure any progress in abilities and skill. These assessments are done by having the athlete perform a series of tests that will measure a variety of fitness areas.

One such test is the vertical jump test, which is used to measure maximal leg power. Different methods have been designed over time to measure maximal vertical jump ability. Many strength and conditioning coaches will invest in a commercial device specifically designed for measuring vertical jump: such as Just Jump or Run ${ }^{\circledR}$, Long Jump Test ${ }^{\circledR}$, Jump Rack ${ }^{\circledR}$, or the more commonly used Vertec ${ }^{\circledR}$. However, the same results may be obtained by simply using the wall and chalk technique. The wall and chalk technique is done by having the athlete place some chalk on their finger tips, jumping next to a wall and marking their maximum height on the wall with their fingers.

Other devices have also been designed that measure additional components to a maximum jump test. Force plates have the ability to measure the amount of force and power exerted by a working muscle. One such force plate is the Kistler Quattro Jump® (Amherst, NY 14228) force plate. Along with maximum jump height, it also measures the force, power, and endurance of the leg muscles. Jump height is mathematically calculated by flight time.

This literature review identified only one study that examined the reliability of using a force plate to measure jump height is that of Isaacs et al[23]. They compared the Just Jump System $®$ (Hunstville, AL 35802) with the Vertec $®$ (Hilliard, OH 43026) to measure maximum jump height. The Just Jump System $(\mathbb{R}$ is similar to a force plate such as the Kistler Quattro Jump ${ }^{\circledR}$ where jump height is calculated by flight time. The subjects' jumps were simultaneously measured by placing the Just Jump mat directly 
under the feet of the subjects and the Vertec $®$ directly in front of them. They concluded that there was a significant difference between the two tests (.93 inches)[23]. However, both systems are an acceptable method for measuring maximum jump height. Using one or the other consistently when testing individuals will still reveal any short-term or longterm gains in a training program. However, since force plates are used throughout the athletic community as a method for measuring training status, it is imperative that investigations conduct further reliability tests to determine the effectiveness of force plate measurements.

\section{Types of Stretches}

Four types of stretches have been discussed in the literature: static, ballistic, proprioceptive neuromuscular facilitation (PNF), and dynamic. These stretches are discussed below.

\section{Static Stretching}

Static stretching is one of the most common methods used for increasing flexibility and range of motion. Static stretching involves passively stretching into a near maximal position and holding for an extended (15-30 seconds) period of time. The key qualities of static stretching are maximum control, little or no movement, and minimal to no velocity of movement [33]. It is also believed that long term effect of static stretching will reduce the risk of injury, decrease muscle stiffness or the muscle-tendon unit leading to an increase in range of motion, alleviate pain, and improve athletic performance [13]. However, no evidence in the literature has been able to support any benefits that acute static stretching has on performance. Recent studies have shown static stretching to 
actually have a detrimental effect on force, balance, power output, as well as maximum vertical jump height[7, 13, 15, 16, 18, 19, 27, 34-36].

\section{Ballistic Stretching}

Ballistic stretching is a rapid, bouncing movement in which the body part is put into motion and momentum carries it through the range of motion (ROM) until the muscles are stretched to their limits [37]. Ballistic stretching has become one of the more controversial topics in sports and exercise science caused in part by the lack of research [33]. Research in this area of stretching is lacking because performing ballistic stretches places the person at a higher risk for injury caused by exceeding the extensibility limits of the tissues involved. Ballistic stretching is performed at high speeds, making it difficult to control the rate and degree of stretch as well as the amount of force being applied [37]. Due to this higher risk of injury, there is very little research on the effects of ballistic stretching. However, literature does exist that supports ballistic stretching $[33,38]$.

Arguments supporting ballistic stretches are based on the following advantages: development of dynamic flexibility, effectiveness, team camaraderie, and interest [33]. Because most activities and movements are dynamic, ballistic stretching permits specificity in training and warm-up. Another advantage of ballistic stretching includes the improvement of reflex reactions due to an increase in neural adaptations involving the reflex responses [38]. Because of these advantages, strength and conditioning coaches will often incorporate a ballistic training program for athletes also known as plyometric training. However, only one study has tested the effects of acute ballistic stretching prior to physical activity and found it to have no significant effect on vertical jump performance in trained women[13]. 
PNF stretching was first designed by physical therapists as part of a neuromuscular rehabilitation program [39]. It has since become widely accepted as a more appropriate method for increasing ROM when compared to other stretching techniques. Studies have proven that PNF stretching is superior to all other methods for increasing ROM $[12,32,40]$. Performing a PNF stretch involves both passive and active muscle actions resulting in a greater stretch when compared to other techniques. Most PNF stretches require the use of a partner making it impractical to perform alone.

PNF stretching is conducted by first assuming an initial passive stretch, followed be an isometric contraction held for approximately 15-25 seconds. Following the contraction the muscle is relaxed for $2-3$ seconds and then immediately subjected to a passive stretch. The isometric contraction fatigues the muscle spindles, allowing a much deeper stretch resulting in greater gains in ROM [33].

Acute PNF stretching has also been shown to have even more detrimental effects on performance when compared to static stretching. Studies have shown that PNF stretching results in greater loss in strength, power output, as well as maximum vertical jump height when compared to static stretching $[18,20]$.

\section{Dynamic Stretching}

Dynamic stretching is the act of moving a joint through its entire range of motion in a quick manner with little resistance. It is not as commonly used as the three previous methods discussed but has become more popular over the last couple of years [21, 37]. Dynamic stretching consists of exercises that are functionally based and incorporate sport-specific movements to prepare the body for activity[24]. The stretches are designed 
in a manner that replicates repetitive movements identical to those performed during an athletic event or exercise session. Some of the benefits of dynamic stretching include raising of core body and deep muscle temperatures, stimulation of the nervous system, decreases in the inhibition of antagonist muscles, increases postactivation potentiation and possibly reduces the risk of injury $[21,24]$. Due to the lack of research it is not known if dynamic stretching can increase ROM. Only one study has tested the effects of acute dynamic stretching on performance and they found that performing one set of dynamic stretches increased leg extension power[21].

\section{$\underline{\text { Stretching and Performance }}$}

Past research on stretching focused on the impact of static stretching as well as PNF techniques and the amount of time to execute the stretches in order to increase ROM $[4,9-12]$. Those investigations found that PNF results in larger gains, however requires the use of a partner. Since static stretches can be performed without a partner, it has become the preferred method for increasing ROM. More recent investigations have studied the acute effects that stretching has on performance. Some of these studies concluded that acute stretching neither helped nor inhibited performance[13-15], whereas other studies demonstrated negative performance effects [7, 16-19]. Table 1 shows a list of recent studies that tested the effects of acute stretching, their outcome measures and findings, the type of stretch, and sets completed.

Based on these studies there is substantial evidence to conclude that static stretching should not be performed as part of a warm-up for enhancing performance. Performing static stretches has a calming effect on the body[24] and the lack of friction 
Table 1

\begin{tabular}{|c|c|c|c|}
\hline Author & Outcome Measures & Findings & Time of Stretch and Sets \\
\hline $\begin{array}{l}\text { Behm, et al. } \\
2004\end{array}$ & Force, balance, reaction time & $\downarrow$ in force and balance & $\begin{array}{l}3 \text { sets of static stretch held for } 45 \\
\text { seconds each }\end{array}$ \\
\hline $\begin{array}{l}\text { Church, et al. } \\
2001\end{array}$ & Vertical jump height (cm) & $\begin{array}{l}\downarrow \text { in vertical jump with } \\
\text { static and PNF }\end{array}$ & $\begin{array}{l}\text { Static Stretch: Number of sets } \\
\text { not reported } \\
\text { PNF: } 3 \text { sets held for } 10 \text { seconds } \\
\text { each }\end{array}$ \\
\hline $\begin{array}{l}\text { Cornwell, et al. } \\
2002\end{array}$ & Vertical jump height $(\mathrm{cm})$ & $\downarrow$ in vertical jump & $\begin{array}{l}3 \text { sets of static stretch held for } 30 \\
\text { seconds each. }\end{array}$ \\
\hline $\begin{array}{l}\text { Knudson, et al. } \\
2001\end{array}$ & Vertical velocity & $\begin{array}{l}\text { Non-significant } \downarrow \text { in } \\
\text { vertical jump velocity }\end{array}$ & $\begin{array}{l}3 \text { sets of static stretch held for } 15 \\
\text { seconds each. }\end{array}$ \\
\hline $\begin{array}{l}\text { Marek, et al. } \\
2005\end{array}$ & $\begin{array}{l}\text { Peak torque and mean power } \\
\text { during isokinetic leg } \\
\text { extensions }\end{array}$ & $\begin{array}{l}\downarrow \text { in strength and power } \\
\text { output }\end{array}$ & $\begin{array}{l}4 \text { sets of static stretch and PNF } \\
\text { held for } 30 \text { seconds each. }\end{array}$ \\
\hline $\begin{array}{l}\text { Unick, et al. } \\
2005\end{array}$ & Vertical jump height & $\begin{array}{l}\text { No significant difference } \\
\text { in vertical jump height }\end{array}$ & $\begin{array}{l}3 \text { sets of static and ballistic } \\
\text { stretch held for } 15 \text { seconds each. }\end{array}$ \\
\hline $\begin{array}{l}\text { Yamaguchi, et } \\
\text { al. } 2005\end{array}$ & Leq extension power & $\begin{array}{l}\downarrow \text { in leg extension power } \\
\text { following static stretch } \\
\uparrow \text { in leg extension power } \\
\text { following dynamic stretch }\end{array}$ & $\begin{array}{l}1 \text { set of static stretches held for } \\
30 \text { seconds. } \\
1 \text { set of dynamic stretches } \\
\text { performed } 10 \text { tens for each } \\
\text { muscle group. }\end{array}$ \\
\hline
\end{tabular}


from the muscle's sliding filaments leads to a cooling down of the muscle instead of warming up[33]. Some other physiological changes that could also be occurring as a result of this calming effect are a decrease in heart rate, decreased body temperature, as well as a decrease in energy production. These changes also result in a cooling down of the entire body. Therefore acute static stretching should only be performed post exercise and for the purpose of increasing ROM. However, further research is needed to draw any conclusions on the effects of acute ballistic stretching and dynamic stretching on performance.

Of the studies listed in Table 1, only one tested the effects of acute ballistic stretching on vertical jump performance. Unick et al. found no significant difference on vertical jump height after performing 3 sets of ballistic stretches for 15 seconds each in trained women. After performing the 3 sets of ballistic stretches the subjects walked on a treadmill for four minutes prior to the vertical jump test. This four minute walk may have had some effect on the impact of the stretch routine. They also proposed that their varying results may have been attributed to gender and the fact that all subjects were trained athletes currently involved in plyometric training. The subjects' involvement in plyometric training alone could have severely skewed the results caused by muscle fatigue and/or delayed onset muscle soreness (DOMS), or they may have reached their peak level of performance and therefore could not obtain anymore gains in performance.

\section{Stretch Shortening Cycle}

The stretch shortening cycle (SSC) refers to a natural part of most movements. It is performed in a sequence of eccentric, isometric, and concentric actions. The stretch 
shortening cycle generates natural elastic energy in a reflex manner common in many everyday movements. For example, while walking the quadriceps go through an eccentric contraction when your foot hits the ground, followed by an isometric contraction, and finally a concentric contraction. This chain of events assists in propelling your body forward as you are walking or even running[41]. When the sequence of contractions is performed quickly a slight stretching occurs in the muscle. This slight stretching stores elastic energy that in turn produces more force in the concentric contraction that follows the slight stretch. Without the stretch shortening cycle the action would only produce small amounts of force and power.

The stretch shortening cycle is demonstrated in many different sporting events. It can be seen in a baseball game when the pitcher winds up for a pitch or when the outfielder jumps to catch a fly ball. Basketball players would not be able to dunk a basketball if it was not for the stretch shortening cycle generating additional force to help propel them into flight. Even boxers rely on the stretch shortening cycle to generate more force when throwing a punch to knock out their opponent. These movements are also similar to dynamic stretches, allowing a training coach to design dynamic stretches that will mimic sport specific movements.

Dynamic stretches stimulate the muscle spindles in a manner similar to that of plyometric training, which is the preferred method for stretch shortening cycle training[42]. During plyometric exercises, a rapid stretch stimulates the muscle spindles causing an increase in the muscles reflex activity. The activity in the agonist muscle is potentiated due to this reflexive response, leading to an increase in the amount of force the muscle produces[43]. This in turn leads to an increase in the stretch reflex response as 
well as the stretch shortening cycle. Since dynamic stretching stimulates the stretch shortening cycle, decreases the inhibition of antagonist muscles, as well as increases postactivation potentiation it should result in increased vertical jump height and force.

Since plyometric training is often referred to as "ballistic" training one might assume that ballistic stretches would enhance the stretch shortening cycle similar to the way in which ballistic training does. However, one study has shown that this is not the case. Unick et al. found no significant difference in jump height in trained women after performing 3 sets of ballistic stretches[13]. Their research is the only study that examined the short term effects of ballistic stretching on vertical jump performance. It is therefore necessary for scientific research to continue to examine the effects of acute ballistic stretching prior to performance. Additional studies are needed to confirm the neutral results of Unick et al. 


\section{CHAPTER III}

\section{METHODOLOGY}

\section{Power Analysis}

A power analysis was conducted based on the findings of Yamaguchi et al. to determine the number of subjects needed in this investigation for a sufficient level of power. Based on Yamaguchi et al's significant results and sample size of eleven subjects, it was concluded that this investigation needed a minimum of eight subjects for a sufficient level of power set at .95

\section{$\underline{\text { Subjects }}$}

Ten healthy male college students, ages 22 to 34 years, volunteered to participate in this study. Subjects were recruited from the general student population of the Health and Sports Sciences department. Following an explanation of the procedures and risks involved, all subjects signed an informed consent approved by the University of Louisville Human Studies Committee. Once informed consent was received and understood by all subjects they completed a medical history and physical activity readiness questionnaire.

\section{Experimental Design}

A counterbalanced within-subject experimental design was used for this study. The within-subject design controls for subject variability such as individual differences in flexibility, prior stretching knowledge, jumping ability, and experience as well as gender 
[44]. Each subject completed three testing trials on three non-consecutive days (Figure 1), which was administered by a technician other than the primary investigator to eliminate any jumping bias. On day one, subjects reported to the University of Louisville Exercise Physiology Lab for initial testing. During this initial testing session height and weight was recorded and leg length was measured from the greater trochanter to the lateral malleous using a Gulick tape measure. These measurements were obtained and entered into the computer so the force plate software could calculate jump height.

On the first day of testing, prior to the vertical jump test, each subject engaged in a 5 minute walk on a treadmill at a brisk but comfortable self-selected pace as part of a standard warm-up to get the muscles moving and the blood flowing. This procedure was conducted on all testing days, including those that involved stretching. After walking on a treadmill each subject completed three trials of a single countermovement jump on a Kistler Quattro Jump (Amherst, NY 14228) force plate. The force plate measured jump height, power, and force of jump. The average of the second and third trial scores for height, force, and power was recorded by the technician administering the test. The first trial was not included in the average because the protocol did not call for any practice jumps, therefore the first jump of each subject may have been lesser of a true score compared to the second and third jump. Each subject returned for a second test a minimum of two days later and was randomized to one of two conditions, dynamic or ballistic stretching.

Subjects performed a series of five stretches under the supervision of a technician. The technician demonstrated each stretch and then timed the subject as they were engaged in the stretch. After completing two sets of five ballistic stretches or dynamic 
Figure 1

Experimental Design

Day 1

Day 2

Day 3

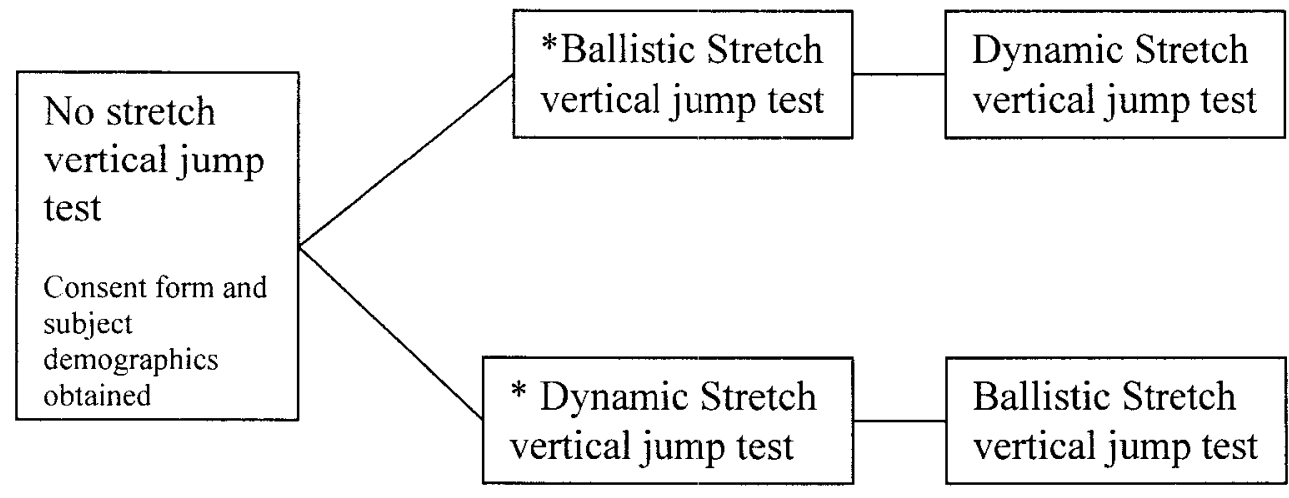

* Subject is randomized to determine if dynamic stretches or ballistic stretches will be performed first. 
stretches the subject completed three more trials of a countermovement jump on the force plate to measure jump height, force, and power. The average of the second and third trial scores for height, force, and power was recorded. A minimum of two days after the second test each subject returned to perform a third and final vertical jump test.

On the third day of testing subjects performed a series of five stretches under the supervision of a technician. The technician demonstrated each stretch and then timed the subject as they were engaged in the stretch. After completing two sets of five ballistic stretches or dynamic stretches (depending upon which one they completed on day 2 of testing) the subject then completed three more trials of a countermovement jump on the force plate to measure jump height, force, and power. The average of the second and third trial scores for height, force, and power was recorded.

\section{Stretching Protocol}

The two types of stretches that were used for this study were ballistic and dynamic stretches. The ballistic stretching protocol consisted of the following five ballistic stretches: forward lunge, supine knee flex, sitting toe touch, quadriceps stretch, and the butterfly. Each subject was instructed to perform the ballistic stretches by bouncing rapidly for 30 seconds at a pace of 126 beats per minute maintained by a metronome. Each subject performed two sets of the stretches. A technician timed each subject so they completed a full 30 second stretch.

Forward Lunge:

Muscles Affected: Hip Flexors (iliopsoas, rectus femoris) 
1. Take a long step forward with right leg and flex right knee until it is directly over the right foot, keeping the right foot flat on the floor and the back leg straight.

2. Keep the back foot pointing towards the front foot. It is not necessary to have the back heel on the floor.

3. Keep torso upright and rest the hands on hips or in front of the leg.

4. Bounce the hips in a forward and downward motion.

5. Repeat for the left leg.

Supine Knee Flex

Muscles Affected: hip extensors (gluteus maximus and hamstrings)

1. Lie on back with legs straight.

2. While bringing the right thigh towards chest, flex the right knee and hip.

3. Place both hands behind thigh and pull the thigh into the chest at a rapid, bouncing pace.

4. Repeat for the left leg.

Sitting Toe Touch

Muscles Affected: hamstrings, spinal erectors, and gastrocnemius

1. Sit with the upper body nearly vertical and the legs straight.

2. Lean forward and attempt to grasp the toes or ankles depending upon limits of flexibility. Begin bouncing the hips keeping the arms extended at all times.

\section{Standing Quadriceps Stretch}

Muscles Affected: Quadriceps

1. Stand upright with one hand extended out against a surface for balance.

2. Flex the right knee and raise your heel to your buttocks. 
3. Grasp your right foot with one hand.

4. Pull your heel towards your buttocks and gently bounce the heel against the buttocks.

5. Repeat with the left leg.

Butterfly

Muscles Affected: hip adductors and sartorius

1. Sitting with the upper body nearly vertical flex both knees, bringing the soles of the feet together.

2. Pull feet toward body.

3. Place hands on feet and elbows on the legs.

4. Bounce the knees up and down by moving the hips.

The dynamic stretching protocol consisted of five stretches that targeted the same muscle area that was stretched in the ballistic routine. Those stretches were: leg kick backs, standing knee raise, calf raise, hurdle step overs, and butt kicks. These stretches were performed five times, slowly at first, and then ten times as quickly and powerfully as possible without bouncing for a total of fifteen repetitions. Each subject completed two sets of each stretch.

\section{Leg Kick Backs}

Muscles Affected: Hip Flexors

1. Stand with one foot balanced on the floor.

2. Raise the other leg slightly off the ground by bending the knee.

3. Kick the leg behind the body and fully extend the leg. 
4. Repeat on the other foot.

Standing Knee Raise

Muscles Affected: Hip Extensors

1. Stand with both feet firmly on the floor.

2. Raise the right leg, bringing the knee as high as possible and raising the thigh towards the chest.

3. Repeat for the left leg.

\section{Calf Raise}

Muscles Affected: soleus and gastrocnemius

1. Start with your body in a push-up position with your feet by your side.

2. Stretch the calves by pushing one heel towards the ground then onto the ball of the foot and then back again.

3. Alternate between legs.

Hurdle Step Over

Muscles Affected: gluteals and hip adductors

1. Stand with one leg slightly further back than the other.

2. Lift the back knee high in front of the body and then rotate the leg outwards and step down.

3. Repeat using other leg.

\section{Butt Kicks}

Muscles Affected: Quadriceps

1. Stand with both feet firmly on the floor.

2. Contract the hamstrings, flex the knee, and kick the buttocks with your heel. 
3. Repeat using other leg.

\section{$\underline{\text { Statistical Analysis }}$}

The statistical analysis was divided into two parts. First, a paired samples $\mathrm{t}$ - test was used to compare mean differences between no stretch and ballistic stretch, and no stretch and as well as no stretch with dynamic stretch across jumping height, force, and power categories. The statistical significance was set at an alpha( $\alpha)$ level of 0.05 . Second, the intraclass reliability for the subjects' jumping height, force, and power performances on the Kistler Quattro Jump $®$ force plate was estimated by the Hoyt's analysis of variance approach, Reliability $=(\mathrm{MSs}-\mathrm{MSi}) / \mathrm{MSs}[45]$. The standard errors of measurement (SEM) were also calculated to quantify the measurement accuracy: SEM = $\mathrm{Sx} \sqrt{1-\text { reliability }}$. All statistical procedures were performed by SPSS version 14 . 


\section{CHAPTER IV}

\section{RESULTS}

Means and standard deviations for each group are presented in Table 2. No subject reported any recent musculoskeletal injuries, taking any over the counter or prescription medications, or engaging in any lower body/high intensity (greater than 17 on rating of perceived exertion scale) training prior to each testing session. The average age \pm standard deviation (SD) was $27.1 \pm 4$ years, the average height \pm SD was $179.9 \pm$ 6.7 centimeters, and the average weight \pm SD of each subject was $81.8 \pm 14$ kilograms. A paired samples t-test was used to determine significance of each stretching protocol on jump height, force, and power.

\section{Effects of Ballistic Stretching}

\section{Vertical Jump}

There was no statistical difference in maximal vertical jump height $(55.9 \pm 9.8$ $\mathrm{cm})$ between no stretch and ballistic stretch $(\mathrm{p}=.37)$. The mean height upon completion of the ballistic stretching routine was $55.9 \pm 9.8 \mathrm{~cm}$. Figure 2 shows each subject's jumping height difference for no stretch and ballistic stretch. Subjects 1 and 2 are outliers in the data and removing them from the statistical analysis changes the $p$ value from .37 to .59 . 
Table 2

Means and Standard Deviations for No Stretch, Ballistic Stretch, and Dynamic Stretch

With Jumping Height, Force, and Power

$\begin{array}{lccc} & \text { No Stretch } & \text { Ballistic } & \text { Dynamic } \\ \text { Jump Height }(\mathrm{cm}) & 54.2 \pm 11.7 & 55.9 \pm 9.8 & 58.3 \pm 11 \\ \text { Force }(\% \text { body weight }) & .87 \pm .31 & .89 \pm .25 & .96 \pm .30 \\ \text { Power }(\mathrm{w} / \mathrm{kg}) & 26.1 \pm 6.6 & 27 \pm 5.5 & 27.2 \pm 5.7\end{array}$




\section{$\underline{\text { Power }}$}

No significant difference was found in maximal power production when comparing no stretch with ballistic stretch $(\mathrm{p}=.56)$. The mean power upon completion of the ballistic stretching routine was $27 \pm 5.5 \mathrm{w} / \mathrm{kg}$. Figure 3 shows the difference in jump power between each subject when comparing no stretch with ballistic stretch. Subjects 1 and 2 are outliers in the data and removing them from the statistical analysis changes the $\mathrm{p}$ value from .56 to .48 .

\section{Force}

No significant difference was found in maximal force production when comparing no stretch with ballistic stretch $(\mathrm{p}=.77)$. The mean force upon completion of the ballistic stretching routine was $.89 \pm .25 \%$ bw. Figure 4 shows the difference in jump force between each subject when comparing no stretch with ballistic stretch.

Subjects 1 and 2 are outliers in the data and removing them from the statistical analysis changes the $\mathrm{p}$ value from .77 to .04 , making it a significant result $(\mathrm{p}<.05)$. 
Figure 2

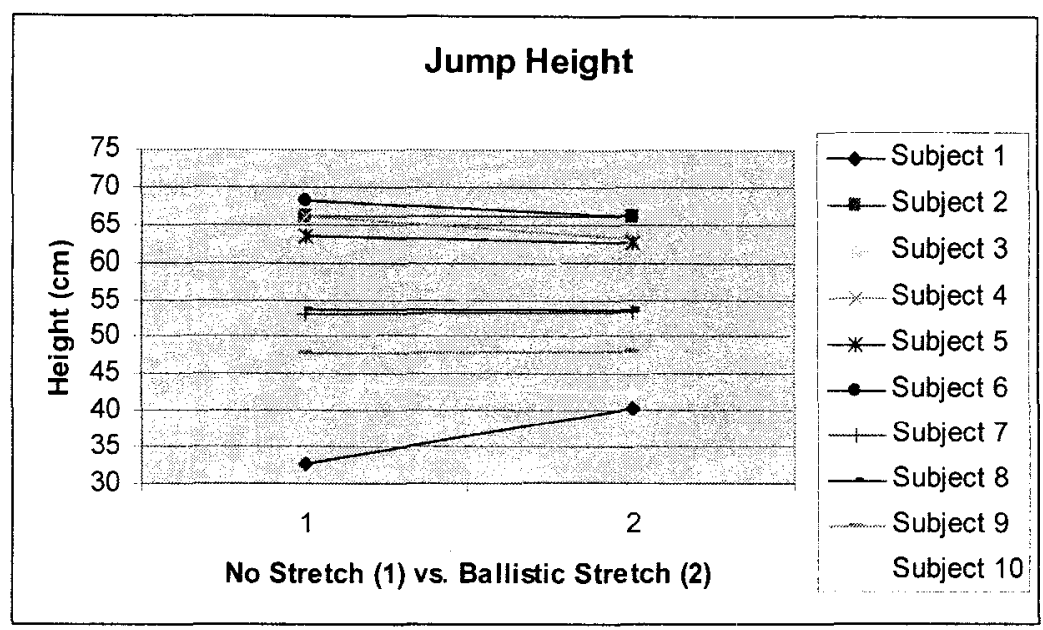

Figure 3

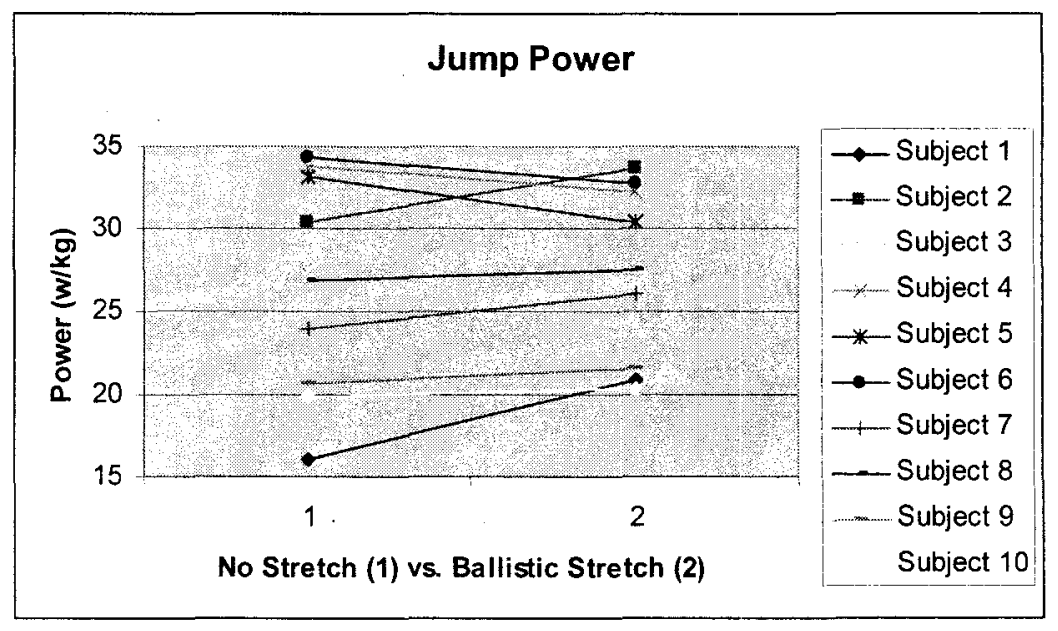

Figure 4

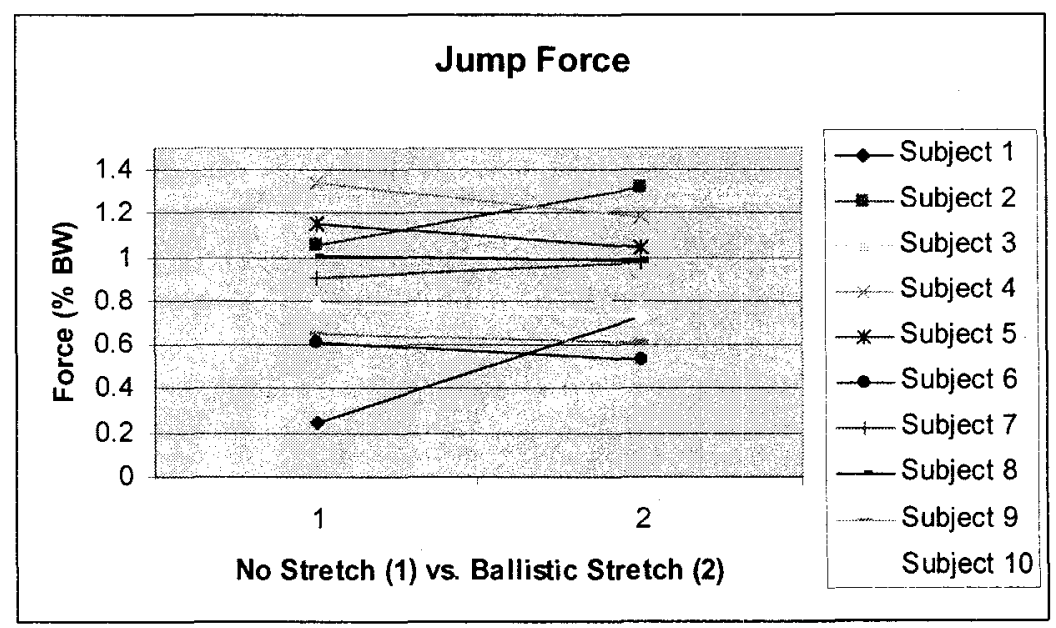




\section{Effects of Dynamic Stretching}

\section{Vertical Jump}

There was no statistical difference in maximal vertical jump height between no stretch and dynamic stretch $(\mathrm{p}=.13)$. The mean height upon completion of the dynamic stretching routine was $58.3 \pm 11 \mathrm{~cm}$. Figure 5 shows each subject's jumping height difference between no stretch and dynamic stretch. Subjects 1 and 2 are outliers in the data and removing them from the statistical analysis changes the $p$ value from .13 to .28 .

\section{Power}

No significant difference was found in maximal power production when comparing no stretch with dynamic stretch $(\mathrm{p}=.07)$. The mean power upon completion of the dynamic stretching routine was $27.2 \pm 5.7 \mathrm{~cm}$. Figure 6 shows the difference in jump power between each subject when comparing no stretch with dynamic stretch. Subjects 1 and 2 are outliers in the data and removing them from the statistical analysis changes the $\mathrm{p}$ value from .07 to .13 .

\section{$\underline{\text { Force }}$}

No significant difference was found in maximal force production when comparing no stretch with dynamic stretch $(p=.52)$. The mean force upon completion of the dynamic stretching routine was $.96 \pm .30 \mathrm{w} / \mathrm{kg}$. Figure 7 shows the difference in jump force between each subject when comparing no stretch with dynamic stretch. Subjects 1 and 2 are outliers in the data and removing them from the statistical analysis changes the $\mathrm{p}$ value from .52 to .31 . 
Figure 5

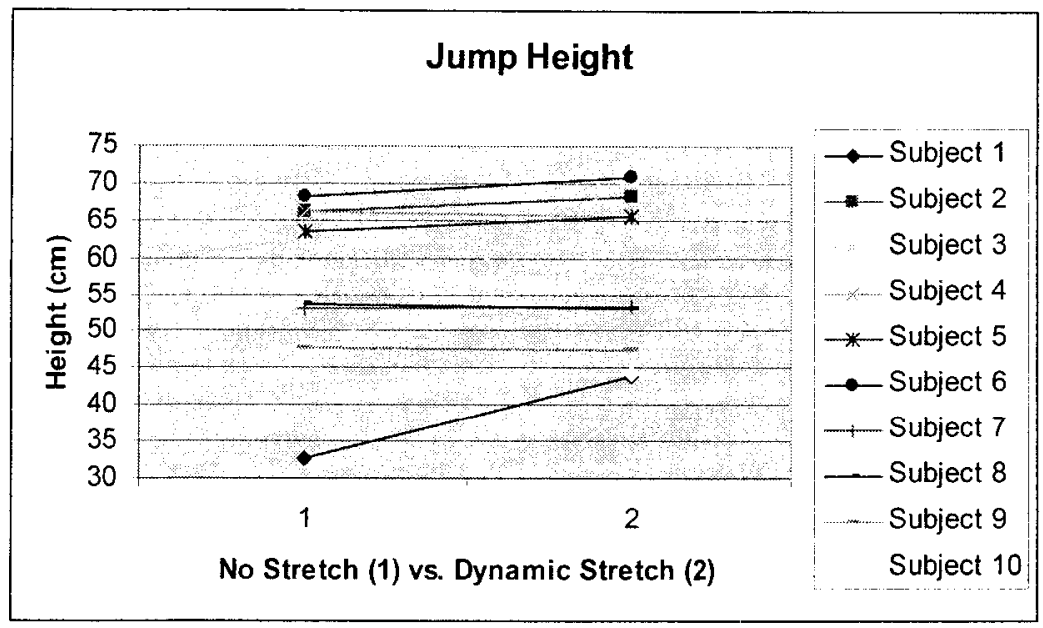

Figure 6

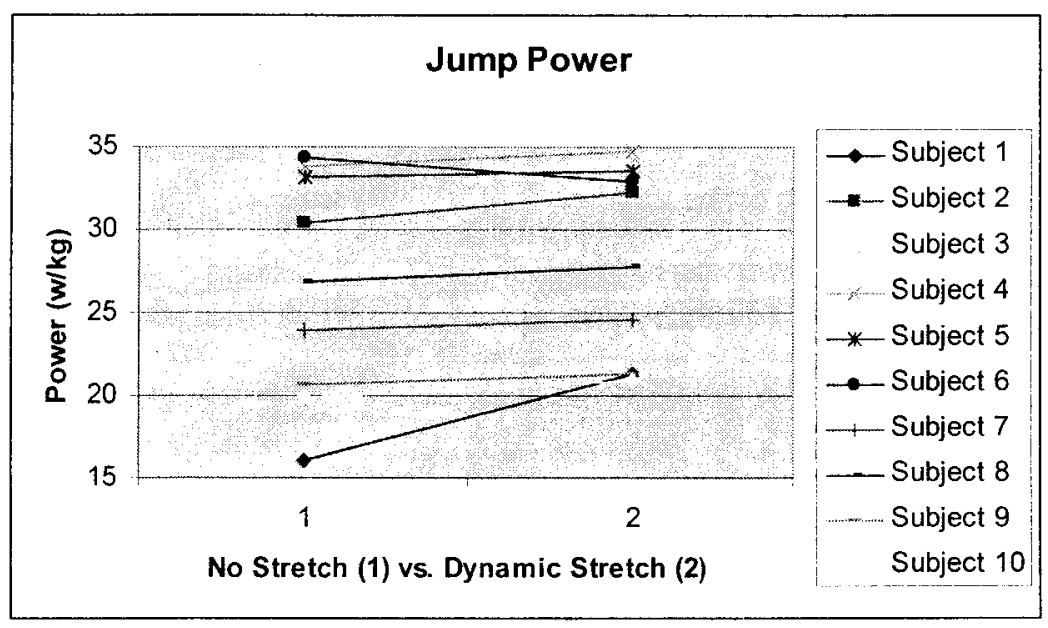

Figure 7

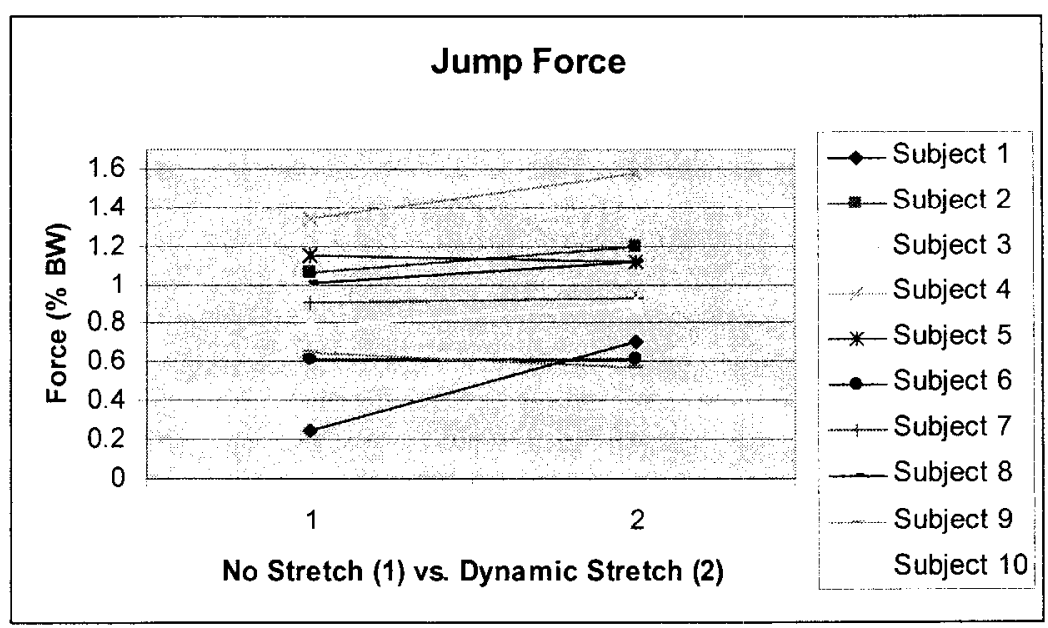




\section{$\underline{\text { Reliability }}$}

Table 3 presents the intraclass reliability of the subjects' jumping performances across three different trials. The reliability coefficients were very high: $>.99$ for jumping height, $>0.94$ for jumping force, and $>.99$ for jumping power. The standard errors of measurement (SEM) are also presented in Table 3. The jumping height was measured to the nearest $\mathrm{cm}$ and all standard errors were lower than $1.7 \mathrm{~cm}$. 
Table 3

Intraclass Reliabilty (Rxx') and Standard Errors of Measurement (SEM) for the Jumping

Height, Force, and Power

Height Force Power

Treatment Rxx' SEM Rxx' $\quad$ SEM Rxx' $\quad$ SEM

$\begin{array}{llllllll}\text { No Stretch } & & .98 & 1.7 & .94 & .08 & .99 & .7\end{array}$

$\begin{array}{lllllll}\text { Ballistic Stretch } & .98 & 1.4 & .97 & .04 & .99 & .55\end{array}$

$\begin{array}{lllllll}\text { Dynamic Stretch } & .99 & 1.1 & .99 & .03 & .99 & .57\end{array}$ 


\section{CHAPTER V}

\section{DISCUSSION}

This study determined the effects of two stretching techniques (ballistic stretch and dynamic stretch) on maximum vertical jump height, force, and power. The results indicate that there was no significant difference in vertical jump height, force, or power when comparing no stretch with ballistic stretch as well as dynamic stretch. Similar findings were reported by Unick et al. when examining the effects of ballistic stretching as part of a warm-up routine prior to physical activity[13]. However, the findings of this study are inconsistent in direction with Yamaguchi et al. who found a significant increase in power production of the leg extensors upon completion of a dynamic stretching routine for warm-up[21].

\section{Ballistic Stretching}

Few studies have examined the effects of ballistic stretching as part of a warm-up routine. Of those examined, only one compared the effects of a ballistic stretching routine on maximum vertical jump height. The finding of the current investigation is consistent with results from Unick et al[13]. They found no significant difference in maximum vertical jump height after completing three sets of a ballistic stretching routine as part of a warm-up. Both investigations used lower body ballistic stretches that focused primarily on the quadriceps and hamstrings. However, Unick et al. used a different subject 
population, recruited more subjects, and also incorporated a four minute walking period in between the stretching routine and vertical jump test. Their subjects consisted of sixteen trained women college basketball players, whereas the current investigation recruited ten males from a more general population. In this investigation only three of the subjects were currently involved in both weight training and cardiovascular training 2-4 days per week. The remaining subjects did not report current physical activity.

The reason for this neutral effect on vertical jump performance is unknown. Other than this particular investigation, Unick et al. are the only researchers to investigate the effects of ballistic stretching on performance variables. Unick et al. associated the neutral effect with the recovery of the motor neuron excitability caused by the Hoffmann reflex (H-reflex)[13]. The H-reflex is similar to the spinal stretch reflex, but instead is able to bypass the muscle spindle directly making it a useful tool for measuring monosynaptic reflex activity in the spinal cord[46]. The H-reflex is an estimate of alpha motor neuron excitability. This measurement can be used to assess the response of the nervous system to various neurological conditions, musculoskeletal injuries, application of therapeutic modalities, pain, exercise training, and performance of motor tasks[47]. According to Avela et al. after completing ten consecutive stretches they found a reduction in the $\mathrm{H}$ reflex[48]. This reduction in the H-reflex as well as motor neuron excitability could lead to a reduction in stretch reflex sensitivity[48]. However, after reviewing the investigation of Avela et al. it is unclear as to whether the reduction in the H-reflex was a result of static stretches or ballistic stretches. Further research needs to be conducted to discover any neural changes within the muscles after acute ballistic stretching. 
Upon removal of the outliers (subjects 1 and 2) from the dataset, the statistical analysis showed a significant decrease in force production $(p=.04)$ after completing two sets of ballistic stretches. Both outliers scored much higher than the remaining eight subjects when comparing no stretch to ballistic stretch in all three performance variables (height, force, power). The reason these two subjects showed tremendous improvement from their baseline jump when compared to the other subjects is unknown.

\section{Dynamic Stretching}

The results of this study add to the conflicting research of other studies when measuring performance variables post warm-up. Yamaguchi et al. found a significant increase in power production after completing a dynamic stretching routine in eleven healthy male subjects[21]. A possible explanation for this contradictory finding could be that all of Yamaguchi's subjects were recreationally active and had a current weight training history. Not all of the subjects in the current investigation were currently in training. Out of the ten subjects, only three reported currently performing any form of weight training or cardiovascular training 2-4 days per week. Also, Yamuguchi et al. had subjects perform only one set of dynamic stretches prior to testing, whereas the stretching protocol in this investigation consisted of two sets of dynamic stretches. It is possible that adding a second set may lead to increased muscular fatigue, resulting in a decreased performance effect.

A more recent investigation by Little et al. found no significant difference in vertical jump height after performing a set of dynamic stretches[49]. This neutral effect clearly agrees with the finding of this study. However, Little et al. also found significant 
increases in speed and agility. Why would some performance variables be enhanced by dynamic stretching but others not? One explanation given by Little et al. was that in their study the subjects performed the vertical jump test first immediately following the dynamic stretch and four minute jogging warm-up. They concluded that it is possible the acute detrimental effects of dynamic stretching may degrade over time since they found significant increases in all other performance variables (speed, agility, and acceleration)[49]. The current investigation also performed the vertical jump test immediately following the stretching protocol which would make it plausible for that explanation.

Evidence provided by Yamaguchi et al. as well as Little et al. suggests that muscular power is enhanced by dynamic stretching. Although the results of this investigation were not significant the only variable that did show a modest trend was that of muscular power. This suggests that if more subjects had been recruited the findings may have been significant.

\section{$\underline{\text { Reliability }}$}

Only one study investigated the interclass reliability of a force plate, and no one has examined the intraclass reliability for measuring jumping performance with a force plate. This study used the results of all three trials of the testing sessions and estimated the intraclass reliability of vertical jump height, force, and power using the Kistler Quattro Jump® force plate. A high reliability was found across all three measurements 
Ten healthy college students participated in two different types of stretching treatments to determine the stretching effects on vertical jump performance. Performance variables (height, force, and power) measured at pre and post stretch indicates no significant difference in any of the three variables. Removing the outliers from the dataset showed ballistic stretching to have a significant decrease in jump force. However, it appears neither dynamic stretching nor ballistic stretching will result in an increase in vertical jump height.

Future investigations should focus on determining any neural changes within the muscle after acute ballistic and dynamic stretching as well as an inclusion of more female subjects. The acute effects of stretching on the upper body should also be looked into more extensively as well. 


\section{REFERENCES}

1. ACSM: ACSM's Guidelines for Exercise Testing and Prescription, 6th ed. Baltimore, MD: Lippincitt Williams \& Wilkins, 2000. (Franklin BA, ed.

2. Cross KM, Worrell TW: Effects of a static stretching program on the incidence of lower extremity musculotendinous strains. J. Athl. Training 1999; 34: 11-14.

3. Hartig DE, Henderson JM: Increasing hamstring flexibility decreases lower extremity overuse injuries in military basic trainees. Am J Sports Med 1999; 27(2): 173-6.

4. Smith CA: The warm-up procedure: to stretch or not to stretch. A brief review. J Orthop Sports Phys Ther 1994; 19(1): 12-7.

5. Hart L: Effect of stretching on sport injury risk: a review. Clin J Sport Med 2005; 15(2): 113.

6. Shrier I: Stretching before exercise does not reduce the risk of local muscle injury: a critical review of the clinical and basic science literature. Clin J Sport Med 1999; 9(4): 221-7.

7. Schilling BK, Stone MH: Stretching: Acute Effects on Strength and Power Performance. J Strength Cond Res 2000; 22(1): 44-47.

8. Young W, Behm D: Should Static Stretching Be Used During a Warm-Up for Strength and Power Actvities? . J Strength Cond Res 2002; 24(6): 33-37.

9. Williford HN, East JB, Smith FH, Burry LA: Evaluation of warm-up for improvement in flexibility. Am J Sports Med 1986; 14(4): 316-9.

10. Bandy WD, Irion JM, Briggler M: The effect of time and frequency of static stretching on flexibility of the hamstring muscles. Phys Ther 1997; 77(10): 1090-6.

11. Walter J, Figoni SF, Andres FF, Brown E: Training intensity and duration in flexibility. Clinical Kinesiology 1996; 50(2): 40-45.

12. Wallin D, Ekblom B, Grahn R, Nordenborg T: Improvement of muscle flexibility. A comparison between two techniques. Am J Sports Med 1985; 13(4): 263-8. 
13. Unick J, Kieffer HS, Cheesman W, Feeney A: The acute effects of static and ballistic stretching on vertical jump performance in trained women. J Strength Cond Res 2005; 19(1): 206-12.

14. Knudson DV, Noffal GJ, Bahamonde RE, Bauer JA, Blackwell JR: Stretching has no effect on tennis serve performance. J Strength Cond Res 2004; 18(3): 654-6.

15. Knudson D, Bennett K, Corn R, Leick D, Smith C: Acute effects of stretching are not evident in the kinematics of the vertical jump. J Strength Cond Res 2001; 15(1): 98-101.

16. Power K, Behm D, Cahill F, Carroll M, Young W: An acute bout of static stretching: effects on force and jumping performance. Med Sci Sports Exerc 2004; 36(8): 1389-96.

17. Fowles JR, Sale DG, MacDougall JD: Reduced strength after passive stretch of the human plantarflexors. J Appl Physiol 2000; 89(3): 1179-88.

18. Church JB, Wiggins MS, Moode FM, Crist R: Effect of warm-up and flexibility treatments on vertical jump performance. J Strength Cond Res 2001; 15(3): 332-6.

19. Behm DG, Bambury A, Cahill F, Power K: Effect of acute static stretching on force, balance, reaction time, and movement time. Med Sci Sports Exerc 2004; 36(8): 1397402.

20. Marek SM, Cramer JT, Fincher AL, et al.: Acute Effects of Static and Proprioceptive Neuromuscular Facilitation Stretching on Muscle Strength and Power Output. J Athl Train 2005; 40(2): 94-103.

21. Yamaguchi $\mathrm{T}$, Ishii $\mathrm{K}$ : Effects of static stretching for 30 seconds and dynamic stretching on leg extension power. J Strength Cond Res 2005; 19(3): 677-83.

22. Young WB, Behm DG: Effects of running, static stretching and practice jumps on explosive force production and jumping performance. J Sports Med Phys Fitness 2003; 43(1): $21-7$.

23. Isaacs LD: Comparison of the vertec and Just Jump Systems for measuring height of vertical jump by young children. Percept Mot Skills 1998; 86(2): 659-63.

24. Fredrick GA, Szymanski DJ: Baseball (part 1): Dynamic flexiblity. Strength Cond J. 2001; 23(1): 21-30.

25. Brooks GA, Fahey TD, Baldwin KM: Exercise Physiology: Human Bioenergetics and Its Applications, 4th ed. New York: McGraw-Hill, 2005. (Barrosse E, ed.

26. Gleim GW, McHugh MP: Flexibility and its effects on sports injury and performance. Sports Med 1997; 24(5): 289-99. 
27. Knudson D: Stretching during warm-up. Do we have enough evidence? . J Orthop Sports Phys Ther 1999; 70(7): 24-27.

28. Cornwell A, Nelson AG, Sidaway B: Acute effects of stretching on the neuromechanical properties of the triceps surae muscle complex. Eur J Appl Physiol 2002; 86(5): 428-34.

29. Garfinkel MS, Singhal A, Katz WA, Allan DA, Reshetar R, Schumacher HR, Jr.: Yoga-based intervention for carpal tunnel syndrome: a randomized trial. Jama 1998; 280(18): 1601-3.

30. Guthrie C: Yoga's Healing Power. Health, vol 19, $2005 ; 7$.

31. Farfan HF: The biomechanical advantage of lordosis and hip extension for upright activity. Man as compared with other anthropoids. Spine 1978; 3(4): 336-42.

32. Holcomb WR: Improved Stretching with Proprioceptive Neuromuscular Facilitation. J Strength Cond Res 2000; 22(1): 59-61.

33. Alter M: Science of Flexibility Third ed. Champaign: Human Kinetics 2004.

34. Burkett LN, Phillips WT, Ziuraitis J: The best warm-up for the vertical jump in college-age athletic men. J Strength Cond Res 2005; 19(3): 673-6.

35. Holcomb WR: Stretching and Warm-Up. In: Baechle TR, Earle R, eds. Essentials of Strength Training and Conditioning, 2nd ed. Champaign, IL: Human Kinetics, 2000; 32141.

36. Kokkonen J, Nelson AG, Cornwell A: Acute muscle stretching inhibits maximal strength performance. Res Q Exerc Sport 1998; 69(4): 411-5.

37. Hedrick A: Dynamic Flexbility Training. Strength Cond J. 2000; 22(5): 33-38.

38. Zehr EP, Sale DG: Ballistic movement: muscle activation and neuromuscular adaptation. Can J Appl Physiol 1994; 19(4): 363-78.

39. Voss DE: Proprioceptive neuromuscular facilitation application of patterns and techniques in occupational therapy. Am J Occup Ther 1959; 13(4, Part 2): 191-4.

40. Sady SP, Wortman M, Blanke D: Flexibility training: ballistic, static or proprioceptive neuromuscular facilitation? Arch Phys Med Rehabil 1982; 63(6): 261-3.

41. Fleck SJ, Kraemer WJ: Designing Resistance Training Programs, 2nd ed. Champaigne, IL: Human Kinetics, 1997. 
42. Malisoux L, Francaux M, Nielens H, Theisen D: Stretch-shortening cycle exercises: an effective training paradigm to enhance power output of human single muscle fibers. J Appl Physiol 2006(100): 771-79.

43. Potach DH, Chu DA: Plyometric Training. In: Baechle TR, Earle R, eds. Essentials of Strength Training and Conditioning

2nd ed. Champaigne, IL: Human Kinetics, 2000.

44. Funk DC, Swank AM, Mikla BM, Fagan TA, Farr BK: Impact of prior exercise on hamstring flexibility: a comparison of proprioceptive neuromuscular facilitation and static stretching. J Strength Cond Res 2003; 17(3): 489-92.

45. Hoyt C: Test reliability estimated by analysis of variance. Psychometrika 1941; 6 : 153-160.

46. Schieppati M: The Hoffmann reflex: a means of assessing spinal reflex excitability and its descending control in man. Prog Neurobiol 1987; 28(4): 345-76.

47. Palmieri RM, Ingersoll CD, Hoffman MA: The Hoffmann Reflex: Methodologic Considerations and Applications for Use in Sports Medicine and Athletic Training Research, J Athl Train 2004; 39(3): 268-277.

48. Avela J, Kyrolainen H, Komi PV, Rama D: Reduced reflex sensitivity persists several days after long-lasting stretch-shortening cycle exercise. J Appl Physiol 1999; 86(4): 1292-300.

49. Little T, Williams AG: Effects of Differential Stretching Protocols During Warm-Ups on High-Speed Motor Capacities in Professional Soccer Players. J Strength Cond Res 2006; 20(1): 203-207. 
Exercise Physiology Lab

\title{
University of Louisville
}

\author{
Informed consent for participation in research activities \\ The Effects of Acute Ballistic and Dynamic Stretching on Vertical Jump \\ Performance \\ HSPPO\# 664.05
}

\section{Introduction}

You have been invited to participate in the research project "The Effects of Acute Ballistic and Dynamic Stretching on Vertical Jump Performance" directed by Jason Jaggers in the Exercise Physiology Lab at the University of Louisville.

\section{Purpose}

Before agreeing to participate in this research study, it is important that you read and understand the information provided. This form describes the purpose, procedures, benefits, risks, discomforts, as well as your right to withdraw from the study at any time.

The purpose of this study is to compare the differences between 2 sets of ballistic stretching and 2 sets of dynamic stretching and the effects they have on vertical jump performance.

This study is expected to last up to 3 months. Your involvement in the study only consists of 3 non-consecutive days in a 7 day time frame. Each test day is expected to take between 15-30 minutes of your time. 10-15 subjects are going to be recruited.

\section{Procedures}

If you agree to participate, you will be asked to sign this consent form. While participating in the study, you are expected to follow all study procedures.

On the first day of testing you will come in to the Exercise Physiology Lab, warm-up by walking on a treadmill at a self-selected pace for five minutes, and perform three trials of a single countermovement jump on a Kistler force plate. Two days later you will return for a second test and then be randomized by drawing from a hat to perform either 2 sets of ballistic stretches or 2 sets of dynamic stretches as part of the warm-up procedure. A trained technician will instruct you during the stretching routines.

After warming up by walking on a treadmill and performing the sets of stretches you will perform three more trials of a single countermovement jump on the force plate. 
For the third and final testing day you will return to the Exercise Physiology Lab two days after your second test and perform the sets of stretches you did not do on the second day followed by three trials of a single countermovement jump on the force plate.

Hospitalization is not required.

\section{Potential Risks and Discomforts}

Any study evaluating the effect of outcomes in a patient population is subject to potential risks. The risks involved in this study of stretching as a warm-up involve the risk of overextending the muscles and/or ligaments causing a strain or possible tearing of the muscle.

The risks mentioned above are those that are foreseeable. There may be risks that are unforeseeable.

\section{Benefits}

There may be no benefit to you for participating in this study. However, this study will provide you and us with a detailed assessment of your jumping ability. It will also help us to understand if incorporating ballistic or dynamic stretches as a warm-up prior to athletic competition will result in increased performance.

\section{Injury Compensation}

You understand that should you be injured in any way during this study, that medical treatment is not available through the Exercise Physiology Lab of the University of Louisville. You further understand that you would be directed to seek treatment by the physician or medical facility of your choice and that you or your insurance company would be responsible for the cost of the treatment. No compensation for treatment of the injury or for costs beyond that of any medical treatment (e.g., to cover lost wages, inconvenience, or discomfort) would be available through the Exercise Physiology Lab, or the University of Louisville. If at any time, you develop symptoms or think you are having a medical problem, you need to call your primary care physician. In the event of a research-related injury, you should contact Jason Jaggers at the Exercise Physiology Lab 502-852-4031.

\section{Payment, Additional Cost}

You will not receive any payment for your participation in this study. There will be no costs to you for any of the treatment or testing done as part of this research. You will not be expected to pay any amount, including co-payments, for trial related activities unless you are injured. Any office visits or additional lab work that is not study-related will not be paid by the study.

\section{Confidentiality}

You also understand that the data will be kept in confidence to the extent permitted by the law, however, absolute confidentiality cannot be guaranteed. It is further understood that the data will be made available if needed to the sponsor/investigator and the Human 
Subjects Protection Program. Data obtained will be kept in a locked desk accessible only by the PI.

If the results of this study are published in medical journals, presented at meetings, or used for other educational purposes, your identity as a participant will remain confidential. By signing this consent, you are authorizing such access.

\section{Questions}

Your signature below attests to the fact that all your present questions have been answered in a language you can understand and that future questions will be handled likewise. You can direct these questions about this research to Jason Jaggers at 502-8524031. This informed consent is not a contract. You are not giving up any legal rights by signing this informed consent document. You will be given a signed copy of this paper to keep for your records. If you have any questions about your rights as a research subject, concerns or complaints about the research or research staff, you may call the Human Subjects Protection Program Office (HSPPO) (502) 852-5188. You will be given the opportunity to discuss any questions about your rights as a research subject, in confidence, with a member of the Institutional Review Board (IRB). The IRB is an independent committee composed of members of the University community, staff of the institutions, as well as lay members of the community not connected with these institutions. The IRB has reviewed this study.

\section{Voluntary Participation/Withdrawal}

You are fully aware that your participation in this study is voluntary and that you may refuse to participate without incurring any penalty or losing any benefits to which you are otherwise entitled. You may also discontinue your participation without incurring any penalty or losing any benefits to which you are otherwise entitled. Any new findings that could affect willingness to participate will be shared with the subject. If you withdraw from the study, no new data about you will be collected for study purposes unless the data concern an adverse even (a bad effect) related to the study. If such an adverse event occurs, we may need to review your medical record. You may withdraw your authorization for us to use all data (other than data need to report and adverse event or to keep track of your withdrawal) that have already been collected, but you must do this in writing. If you decide to withdraw, we ask that you contact Jason Jaggers in writing and let him know that you are withdrawing from the study. Jason Jaggers' mailing address is U of L Exercise Physiology Lab, Crawford Gym, Room \#2, Louisville, KY 40292. At that time, we will ask your permission to continue using all information about you that has already been collected as part of the study prior to your withdrawal.

You understand that you could be removed from the study by the investigator without your consent. The reasons for removal include: failure to follow the experimental procedures and directions provided by the investigator, failure to attend the experimental sessions, and inability to follow experimental procedures.

Your doctor may stop your participation in this study without your consent if circumstances warrant doing so. 


\section{Acknowledgement and Signatures}

Your signature below attests that you have read the methods and risks associated with this research study and freely agree to participate. Your signature also acknowledges having been given a signed copy of the Consent Form.

Subject Signature

Printed Name of Subject

Investigator Signature

Signature of Person Explaining the

Consent Form (if other than investigator)

Printed Name of Person Obtaining Consent
Date Signed

Date Signed

Date Signed 


\section{Master's Thesis Project}

Exercise Physiology Laboratory

Crawford Gymnasium Room \#2

University of Louisville

Louisville, KY 40292

(502) 852-4031

Participant information:

Date:

NAME

HOME ADDRESS

PHONE (HOME)__ (WORK)

NAME OF NEAREST RELATIVE

ADDRESS

PHONE

PERSONAL PHYSICIAN

OFFICE LOCATION

\section{PHONE}

1. PRESENT MEDICATIONS: Please print and spell out each medication, the dosage (usually expressed in $\mathrm{mg}$ ), and the frequency that you take the medications. Include any over-the-counter medication taken within the last 7 days.

2. DRUG ALLERGIES: write "NONE" if you have no drug allergies.

3. SUMMARY: Significant past medical history (surgery, hospitalizations, etc.) 


\section{Master's Thesis Project}

Exercise Physiology Laboratory

Crawford Gymnasium Room \#2

University of Louisville

Louisville, KY 40292

(502) $852-4031$

\section{Medical History Questionnaire}

Name

Date

Weight

Height

Age

\section{GENERAL MEDICAL HISTORY}

Any medical complaints?

Any major illnesses in the past? (Give dates)

Any hospitalizations?

Smoke now?

Packs/day

Smoke in past?

Packs/day

Weight gain in past ten years lbs.

Weight at age 20 30

Diabetes?

Family history of diabetes? Who?

Family history of heart disease? Who? 
Family history of high blood pressure? Who?

Family history of muscular illness? Who?

\section{CARDIO-RESPIRATORY HISTORY}

Any heart disease now? YES / NO

Daily coughing

YES / NO

Any heart disease in past? YES / NO

Cough produces sputum?YES / NO

Heart murmurs?

YES / NO

High blood pressure? YES / NO

Occasional chest pains? YES / NO

Short of breath at rest? YES / NO

Chest pains on exertion? YES / NO

Fainting?

YES / NO

Chest pressure on exertion? YES / NO

\section{MUSCULAR HISTORY}

Any muscle injuries or

illnesses now? YES / NO Muscle pain at rest? YES / NO

Any muscle injuries or

Illnesses in past? YES / NO Muscle pains with exertion? YES / NO

Muscular weaknesses now? YES / NO

\section{BONE JOINT HISTORY}

Any bone or joint (including

Flat feet?

YES / NO

Spine) injuries or illnesses now? YES / NO

Ever had swollen joints? YES / NO

Any bone or joint (including

Spine) injuries or illnesses in past? YES / NO Ever had painful joints? YES / NO

\section{Current physical activity, explain:}


Please explain any "yes" answer above:

Have you exercised in the last 24 hours?

No

Yes- please give detailed description (i.e. Type of exercise, upper/lower body).

Please rate the intensity of the exercise using the RPE scale. (Circle one)

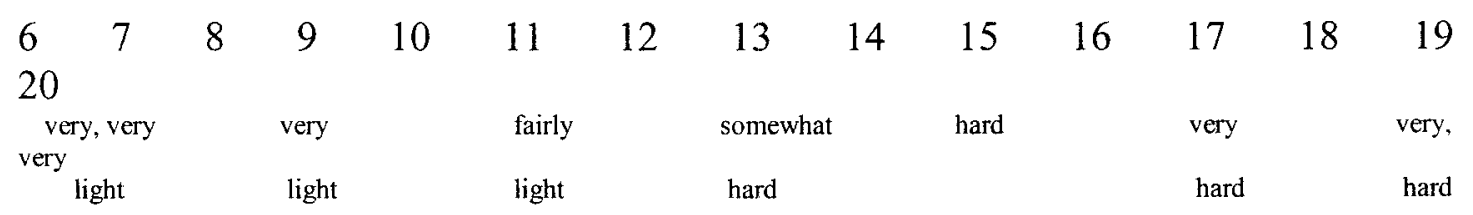


No Stretch

\begin{tabular}{|c|c|c|c|c|c|c|c|c|c|c|c|c|}
\hline \multirow[b]{2}{*}{$\underline{\mathrm{ID}}$} & \multirow[b]{2}{*}{ Age } & \multirow[b]{2}{*}{ Height $(\mathrm{cm})$} & \multirow[b]{2}{*}{ Weight $(\mathrm{kg})$} & \multicolumn{3}{|c|}{ Jump Height $(\mathrm{cm})$} & \multicolumn{4}{|c|}{ Jump Force $(\%$ bw) } & \multicolumn{2}{|c|}{ Jump Power (w/kg) } \\
\hline & & & & 1 & 2 & 3 & 1 & 2 & 3 & 1 & 2 & 3 \\
\hline 1 & 31 & 180.25 & 80.9 & 41.8 & 32.5 & 33.1 & .53 & .25 & .24 & 19.4 & 16.5 & 15.5 \\
\hline 2 & 27 & 180 & 75.5 & 65.9 & 68.1 & 64.3 & .96 & .99 & 1.13 & 28.4 & 29.5 & 31.3 \\
\hline 3 & 25 & 180.5 & 68.4 & 48.6 & 47 & 46.4 & .66 & 1.05 & .86 & 22.6 & 23 & 20.9 \\
\hline 4 & 22 & 168.5 & 61.6 & 66.2 & 67.4 & 64.9 & 1.43 & 1.38 & 1.3 & 33.3 & 33.7 & 33.9 \\
\hline 5 & 25 & 177.8 & 86.13 & 71 & 63.1 & 64.1 & 1.03 & 1.08 & 1.21 & 29.9 & 32.7 & 33.6 \\
\hline 6 & 24 & 176.25 & 72.7 & 73.5 & 70 & 66.1 & .53 & .62 & .6 & 32.8 & 35.5 & 33.3 \\
\hline 7 & 34 & 190 & 101.8 & 56.6 & 55.6 & 50.3 & .71 & .87 & .95 & 24.4 & 23.9 & 24 \\
\hline 8 & 24 & 191 & 96.4 & 45.4 & 54.2 & 53 & 1.3 & .86 & 1.16 & 27.9 & 26.3 & 27.3 \\
\hline 9 & 32 & 176.25 & 73.9 & 46.7 & 48.5 & 47.3 & .66 & .66 & .63 & 20.7 & 21.1 & 20.3 \\
\hline 10 & 27 & 178 & 101 & 45.5 & 42.4 & 45 & .75 & .79 & .76 & 20.2 & 19.7 & 19.85 \\
\hline
\end{tabular}

Ballistic Stretch

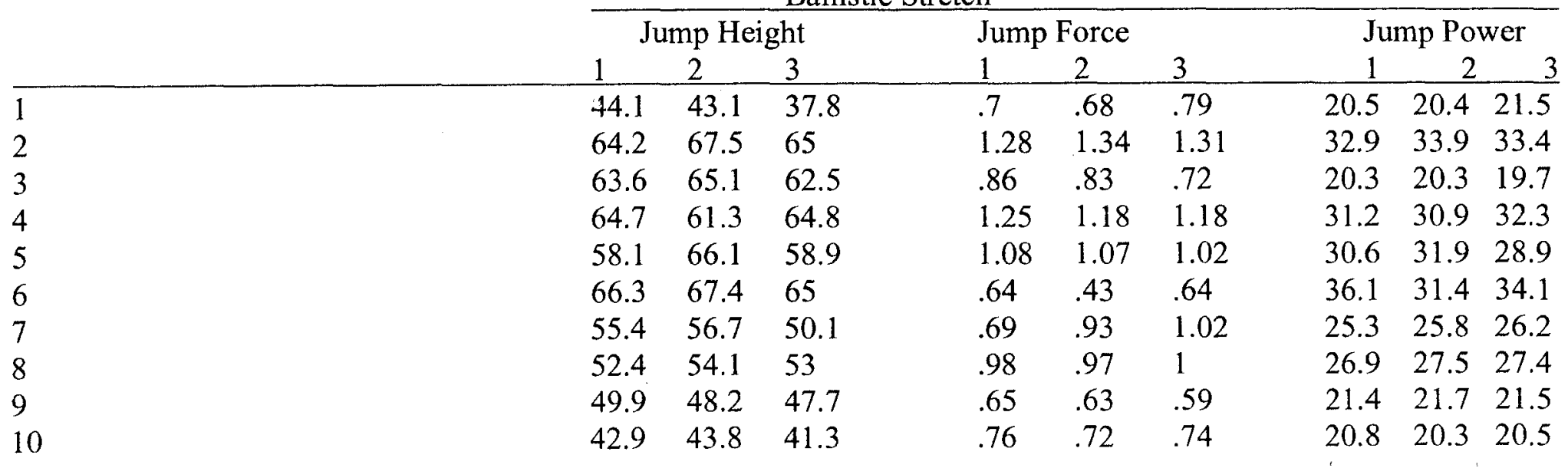


Dynamic Stretch

\begin{tabular}{lllllllllll} 
& \multicolumn{3}{c}{ Jump Height } & \multicolumn{3}{c}{ Jump Force } & \multicolumn{3}{c}{ Jump Power } \\
ID & 1 & 2 & 3 & \multicolumn{1}{c}{1} & 2 & 3 & \multicolumn{2}{c}{1} & 2 & 3 \\
\hline 1 & 40.3 & 46.1 & 41.8 & .56 & .7 & .7 & 19.1 & 21.6 & 21.1 \\
2 & 66.1 & 68.8 & 67.6 & 1.22 & 1.22 & 1.18 & 31.8 & 33.5 & 30.9 \\
3 & 64.3 & 71.1 & 70.2 & .72 & .85 & .95 & 21.6 & 22.2 & 23.1 \\
4 & 70.7 & 67.8 & 63 & 1.7 & 1.62 & 1.54 & 35 & 34.7 & 34.8 \\
5 & 63.8 & 66.5 & 64.8 & 1.1 & 1.12 & 1.11 & 32.6 & 34.4 & 32.6 \\
6 & 67.4 & 72.7 & 68.8 & .55 & .61 & .63 & 33.6 & 32.8 & 33.1 \\
7 & 55.9 & 52 & 54.8 & .93 & .89 & .96 & 26.1 & 23.9 & 25.4 \\
8 & 53.1 & 54.3 & 51.6 & .98 & 1.07 & 1.16 & 27.1 & 28 & 27.5 \\
9 & 48.1 & 47.3 & 47.8 & .6 & .58 & .56 & 21.5 & 21.1 & 21.6 \\
10 & 44 & 45.8 & 42.6 & .76 & .91 & .87 & 20.7 & 21 & 20.9
\end{tabular}




\section{CURRICULUM VITAE}

\section{Jason Jaggers, BS}

\section{Personal Information}

Home Address: 1481 Saint James Ct. Louisville, KY 40208 502.333.0457

Email Address: jason.jaggers@louisville.edu
Work Address: University of Louisville Exercise Physiology Lab Crawford Gym Rm \#2 Louisville, KY 40292 502.852 .4031

\section{Education}

M.S. Exercise Physiology, University of Louisville, Louisville, KY (Graduation: May 2006)

B.S. Exercise Science and Sports Medicine, University of Louisville, Louisville, KY 2004

\section{Work Experience}

Graduate Research Assistant: National Institute of Health (National Institute for Nursing Research) funded grant entitled "Pre-habilitation with TKA." PI - Dr. Bob Topp.

May 2005 - present

Research Assistant: National Heart, Lung, and Blood Institute (NHLBI) sponsored trial entitled: Heart Failure: A Controlled Trial Investigating Outcomes of Exercise TraiNing (HF-ACTION).

PI - Dr. Ann Swank. February 2005 - June 2005

Personal Trainer: Hester's Family Fitness. Louisville, KY. July 2004 - present

\section{Publication in Progress}

Jaggers, J., Simpson, C., Frost, K., Quesada, P., Topp, R., Swank, A., Nyland, J. Prehabilitation Prior To Knee Arthroplasty Increases Post Surgical Function: A Case Study. (sent for publication) 


\section{$\underline{\text { Research Interests }}$}

Exercise and its effects on:

- HIV/AIDS

- Stress management

- Immune System

\section{National Membership Societies}

American College of Sports Medicine, since 2004

National Strength and Conditioning Association, since 2005 